\title{
Prospects for the Control of Solidification Structures from the Viewpoints of Weld, Hot-workability and Near Net Shape Casting
}

\author{
Hidekazu TODOROKI, Makoto OIKAWA, Kung WANG, Yutaka KOBAYASHI and Teruaki ISHII \\ Nippon Yakin Kogyo Group, Yakin Kawasaki Co., Ltd. Technology Development Department, 4-2 Kojimacho, Kawasakiku, \\ Kawasakishi, Kanagawaken 210-8558 Japan. E-mail: todoroki@nyk.co.jp
}

(Received on May 16, 2007; accepted on September 1, 2007)

\begin{abstract}
Solidification structures often determine the quality of final products. In this study, three different phenomena related to solidification processing, which are welding, hot-workability and investment casting, have been summarized.

With non-filler welding of SUS836L strips by TIG, segregation of welded material deteriorated corrosion resistance at the bead because of lower $\mathrm{Cr}$ and $\mathrm{Mo}$ concentrations at the dendrite cores. Employing filler material with higher pitting resistance equivalent (PRE) improved this deterioration. Next, it was confirmed that hot-workability of a stainless steel containing 1.1 mass $\%$ boron that has eutectic solidification behavior was more excellent with CC slabs than ingots. This reason is attributed to the fact that the eutectoids consisting of austenite and boride with the $\mathrm{CC}$ slab are much finer. Cracks at the stem-like corners of investment casts were often found by the magnetic particle testing. It was considered that the cracks were caused with this position being hot spots. The cracking was improved by changing the size of sprues for molten steel not to hit the corners to prevent hot spots.

As a summary, for high alloys, solidification process still depends on the way of try and error and experience base. Therefore far more investigations are expected to predict how molten steels solidify avoiding any defects and deterioration of every property.
\end{abstract}

KEY WORDS: solidification; hot-workability; welding; super stainless steel; segregation; investment casting; cracking; continuous casting; near net shape casting.

\section{Introduction}

Solidification structures significantly influence not only quality of final products but also hot-workability. A molten alloy solidifies along with segregation whose extent depends upon alloy compositions. High-alloys such as stainless steels and Ni-base super alloys are in particular enhanced in this view. Day after day, great efforts have been dedicated to minimize the segregation resulted from solidification with a various ways including heat treatments and deformation at high temperatures. However, significant segregation may remain in the case of welding that must, in fact, be carried out for fabrication of relatively large constructions such as containers for chemicals, foods and fuels. Corrosion usually proceeds on the bead and/or heat affected zone (HAZ) prior to the materials.

Solidification structure may occasionally deteriorate hotworkability at high temperatures. Secondary phases such as carbides, nitrides, sulfides and metallic compounds and so on are formed during or immediately after solidification. Because some of these phases are brittle, one has to pay attention not to cause cracking focusing on heating temperature, reduction rate and so on when hot-rolling or forging.

For near net shape casting process such as foundry work, defects are sometimes fatal because a cast can not be repaired much. Therefore, a careful design of a mold is nec- essary to have a sound cast with no defect. One must account for where, how large and how many sprues and risers will be positioned.

This paper will summarize three different industrial examples. ${ }^{1-5)}$ The first topic is related to the quality of welded metal compared with mother strip. SUS836L (UNS S32053) $)^{1,2,6)}$ known as one of austenitic super stainless steels with corrosion resistance as excellent as Ni-base super alloys is employed for environment, in which SUS304 or SUS316L can not be applied. An example applied for soy source tanks ${ }^{6)}$ is shown in Fig. 1. To fabricate the tanks a number of welds are conducted. A way how to prevent prior corrosion on the welded metal will be documented.

The effect of eutectoid size on hot-workability will be secondly demonstrated for a stainless steel containing

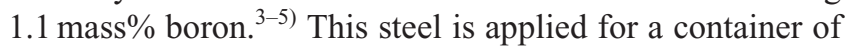
wasted nuclear fuels because boron has an ability to absorb neutrons when ${ }^{10} \mathrm{~B}$ changes ${ }^{11} \mathrm{~B} .{ }^{5)}$ Boron is an element wellknown as a large amount of isotopes naturally existing. Many researchers pointed out that this steel had a susceptibility to cracking owing to very poor hot-workability. ${ }^{3-5,7-10)}$ The solidification pass of this alloy system is eutectic with primary austenite $(\gamma)$ phase and subsequent eutectoids of $\gamma$ and borides. ${ }^{3-5,9,10)}$ Due to this behavior, tensile strength does not appear until solid fraction reaches unity. ${ }^{9)}$ This study will give an idea to improve the brittle behavior con- 
trolling boride size.

Improvement of an investment casting of SCM415 by means of lost wax method will be lastly introduced. The product is used for a cam shaft for an automobile shown in Fig. 2. It was problematic that the stem-like corners closest to the sprues were often cracked while the other sides were not cracked. Yield of this product was very low because the cracked part could not be repaired. Prevention of this crack has been succeeded with redesigning a mold.

Based on the above studies, the expected future work will be suggested as the prospects in solidification process.

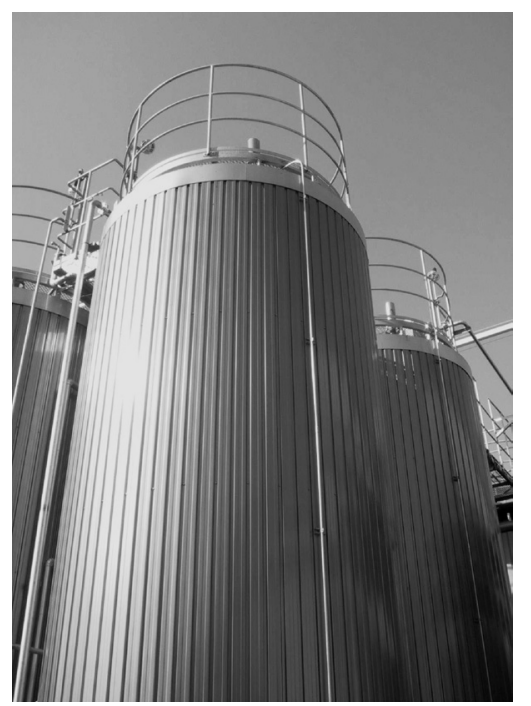

Fig. 1. Tanks made of SUS836L for soy source.

\section{Experimental Details}

\subsection{Welding}

SUS836L strips with $4 \mathrm{~mm}$ in thickness, whose composition is provided in Table 1, were welded by TIG. The strips were produced through the process shown in Fig. 3; melting and refining were conducted by electric furnace (EF), argon oxygen decarburization (AOD), vacuum oxygen decarburization (VOD) and ladle furnace (LF). The molten steel was finally cast by means of continuous caster (CC). Slab surfaces were ground and reheated at the furnace followed by hot-rolled and cold-rolled.

The detailed welding conditions are documented elsewhere. ${ }^{1)}$ Four passes of weld were carried out with the welding current ranging from 100 to 150 (A) depending on the pass sequence. Ar gas was employed as the sealed gas with the flow rate between 15 and $20(\mathrm{~L} / \mathrm{min})$. The welding speed was between 50 and $120(\mathrm{~mm} / \mathrm{min})$. For comparison
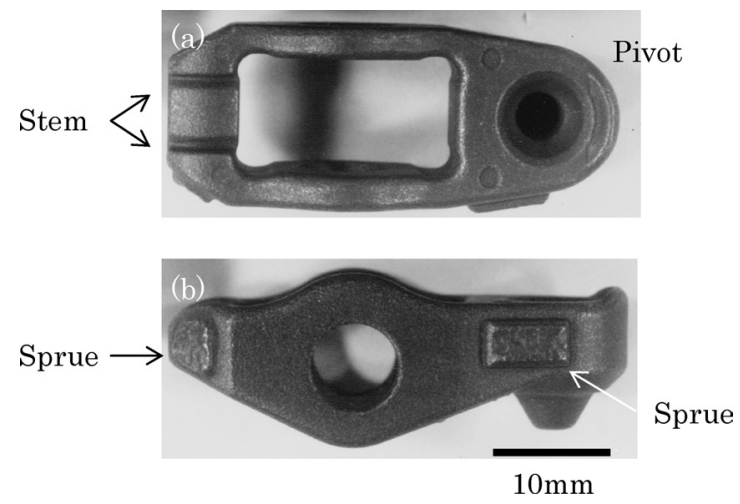

Fig. 2. A locker arm made of SCM415 from (a) top and (b) side views.

Table 1. Chemical composition of SUS836L (mass\%).

\begin{tabular}{|c|c|c|c|c|c|c|c|c|c|c|}
\hline & $\mathrm{C}$ & $\mathrm{Si}$ & $\mathrm{Mn}$ & $\mathrm{P}$ & S & $\mathrm{Ni}$ & $\mathrm{Cr}$ & Mo & $\mathrm{N}$ & $\operatorname{PRE}(*)$ \\
\hline & $\leqq 0.030$ & $\leqq 1.00$ & $\leqq 2.00$ & $\leqq 0.045$ & $\leqq 0.030$ & $\begin{array}{c}24.00 \sim \\
26.00\end{array}$ & $\begin{array}{c}19.00 \sim \\
24.00\end{array}$ & $\begin{array}{c}5.00 \sim \\
7.00\end{array}$ & $\leqq 0.25$ & \\
\hline Typical Example & 0.008 & 0.11 & 0.19 & 0.018 & 0.0005 & 25.58 & 23.21 & 5.56 & 0.205 & 45.7 \\
\hline
\end{tabular}

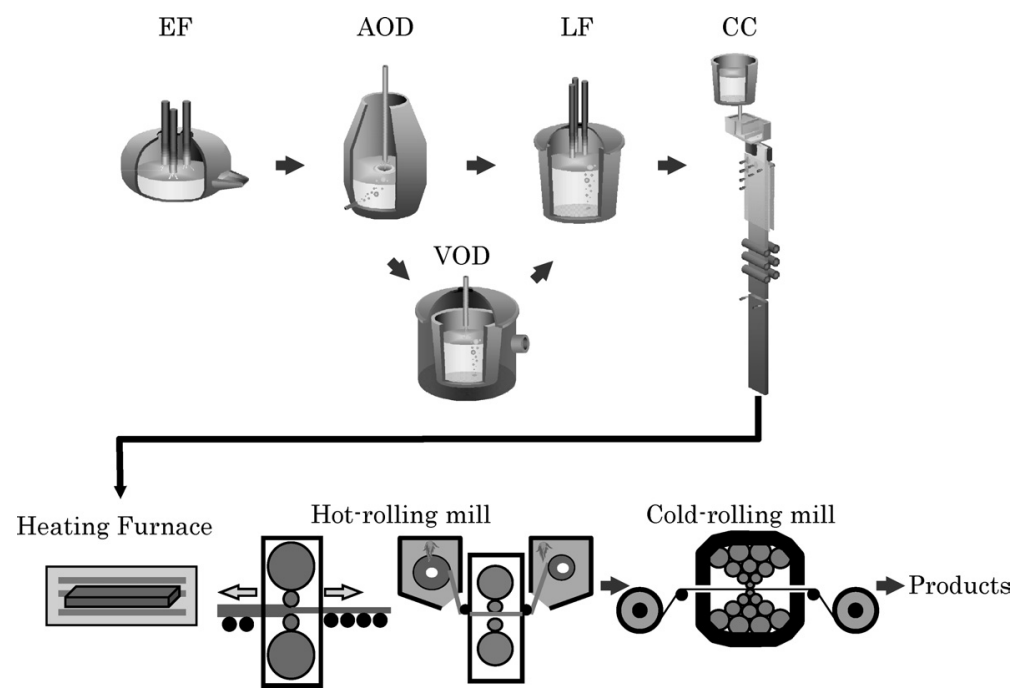

Fig. 3. A typical process for stainless steels. 
Table 2. Chemical composition of stainless steel containing boron (mass $\%$ ).

\begin{tabular}{cccccc}
\hline $\mathrm{C}$ & $\mathrm{Si}$ & $\mathrm{Mn}$ & $\mathrm{Ni}$ & $\mathrm{Cr}$ & $\mathrm{B}$ \\
\hline $0.02 \sim 0.03$ & $0.8 \sim 0.9$ & $0.9 \sim 1.0$ & $10.2 \sim 10.3$ & $18.3 \sim 19.6$ & 1.1 \\
\hline
\end{tabular}

Table 3. Typical chemical composition of SCM415 (mass\%).

\begin{tabular}{cccccc}
\hline $\mathrm{C}$ & $\mathrm{Si}$ & $\mathrm{Mn}$ & $\mathrm{Ni}$ & $\mathrm{Cr}$ & $\mathrm{Mo}$ \\
\hline 0.16 & 0.71 & 0.65 & 0.09 & 1.08 & 0.25 \\
\hline
\end{tabular}

TIG welding was conducted with and without filler material which was ERNiCrMo-4 corresponding to Hastelloy C-276 ( $57 \mathrm{mass} \% \mathrm{Ni}-16 \mathrm{mass} \% \mathrm{Cr}-16 \mathrm{mass} \% \mathrm{Mo}-4 \mathrm{mass} \% \mathrm{~W}-\mathrm{Fe})$.

For preparation cross-sections of the specimens were cut, mounted and polished as mirror finishing. Element distribution was measured by line scans using electron probe micro analyzer (EPMA) to determine how significant segregation was. Aqua regia was used to reveal the solidification structures.

Corrosion resistance at the weld was evaluated according to JIS G0578. The specimen of $25 \mathrm{~mm} \times 20 \mathrm{~mm} \times$ thickness was put into the solution of $6 \% \mathrm{FeCl}_{3}+1 / 20 \mathrm{~N} \mathrm{HCl}$ to know the critical pitting temperature (CPT).

\subsection{Hot-workability}

Prior to the experiments of high-temperature tensile tests, thermal analysis has been conducted to understand solidification behavior. $5 \mathrm{~kg}$ of steels of $\mathrm{Fe}-19$ mass $\% \mathrm{Cr}-10$ mass $\% \mathrm{Ni}$ base with boron contents varying between 0.6 and 1.6 mass $\%$ were molten using an induction furnace. The furnace was then turned off to gradually cool down the steel to measure the temperature variation with time.

The chemical composition of stainless steel containing 1.1 mass $\%$ B is given in Table 2. The specimens were taken from an as-cast slab produced by CC shown in Fig. 3. The technology to continuously cast this steel is documented in the previous report. ${ }^{3)}$

To determine the effect of boride size and morphology on hot-workability, instead of CC slab, the other specimens were taken from an as-cast ingot produced by an up-hill mold after VOD treatment. Every specimen was $\phi 5 \times 70$ $\mathrm{mm}$ in size and high-temperature tensile test was performed using THERMECMASTER-Z. The procedure was that a specimens was heated by an induction coil to $1150^{\circ} \mathrm{C}$ and kept for $60 \mathrm{~s}$ followed by cooled down to the test temperatures of $800,900,1000$ and $1100^{\circ} \mathrm{C}$. The soaked specimen was then deformed until fracture with a strain rate of $5 \mathrm{~s}^{-1}$. For the test temperature of $1200^{\circ} \mathrm{C}$, a specimens was heated to $1200^{\circ} \mathrm{C}$ and kept for $60 \mathrm{~s}$ followed by deformation until fracture.

For preparation cross-sections of the specimens before and after the test were cut, mounted and polished as mirror finishing. Internal solidification structures were revealed by an electrical etching method with $10 \%$ oxalic acid solution with a current density of approximately $1 \mathrm{~A} / \mathrm{cm}^{2}$ for $1 \mathrm{~min}$ at a room temperature.

\subsection{Investment Casting}

The casting called locker arm for cam shaft for automo- bile was investigated. The chemical composition of the steel is shown in Table 3. The steel grade is SCM415 that contains a small amount of $\mathrm{C}, \mathrm{Cr}$ and $\mathrm{Mo}$. The molds were prepared by means of lost wax method as follows. The waxes with the shapes same as the products were attached on the center tree. Twenty waxes were set in a column with four pieces a row radially. A set of eighty molds with a tree was immersed into the alumina slurry and then naturally dried. After that this was gradually heated up to approximately $200^{\circ} \mathrm{C}$ to melt the waxes and take them off outside. Consequently the molds made of alumina were prepared followed by gradually preheated up to $1050^{\circ} \mathrm{C}$ to prevent thermal shock.

The casting procedure was as follows. At first, $200 \mathrm{~kg}$ of the steel was melted in an induction furnace. The molten steel with about $1600^{\circ} \mathrm{C}$ was poured into a ladle from which it was poured into the sets of the prepared molds. The products were detached from the tree with high-velocity vibration after they were naturally cooled down to a room temperature. The products were inspected by magnetic particle testing under the fluorescence light to see if they are with defects.

For preparation cross-sections of the casts involving the indications were cut, mounted and polished with mirror finishing. Substance involved inside a crack was analyzed by an energy dispersion X-ray analyzer (EDS). To reveal the solidification structures, they were immersed into the aqueous solution where $2 \mathrm{~g}$ of picric acid, $0.5 \mathrm{~g}$ of $\mathrm{CuCl}_{2}$ and a drop of detergent were dissolved in water of $100 \mathrm{~mL}$. After the immersion for $5 \mathrm{~min}$, the surfaces were polished again to remove pure copper which was precipitated on the etched surface.

\section{Results and Discussion}

\subsection{Welding}

Corrosion resistance of the welded metal is a key to the life of fabricated containers. The status of corrosion property of SUS836L known as a super austenitic stainless steel, defined as Fe-base steel with $\mathrm{Cr} \geqq 20 \mathrm{mass} \%, \mathrm{Mo} \geqq 5 \mathrm{mass} \%$, $\mathrm{N} \geqq 0.15 \mathrm{mass} \%$, is schematically explained in Fig. 4 accounting for manufacturing cost. It is known that corrosion resistance, especially for pitting, is getting more excellent with increasing $\mathrm{Cr}$, Mo and $\mathrm{N}$ contents. As can be seen, SUS836L is positioned at higher resistance than SUS304, SUS316L and SUS329J4L (a duplex stainless steel). It should be notified that this steel has been developed as a material in between duplex stainless steels and Ni-base super alloys. The benefit is that this steel is excellent 


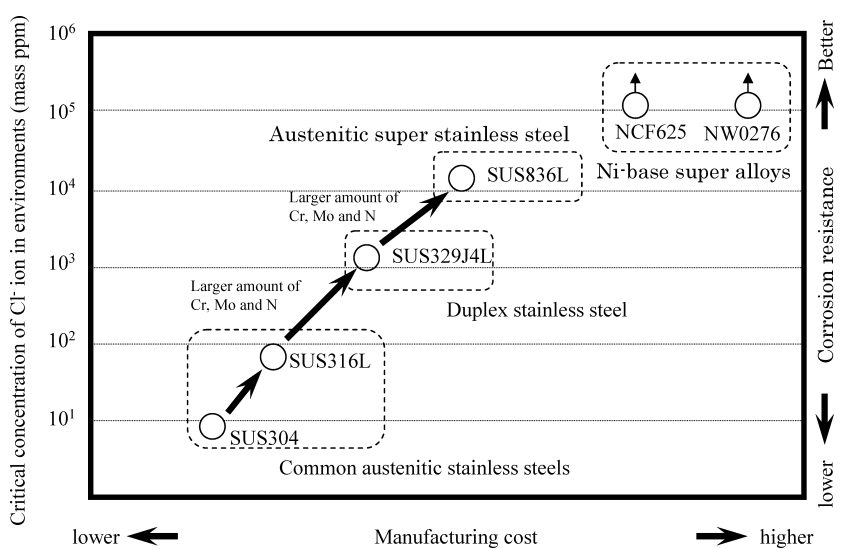

Fig. 4. Characteristic of austenitic super stainless steel featuring larger amounts of $\mathrm{Cr}, \mathrm{Mo}$ and $\mathrm{N}$.

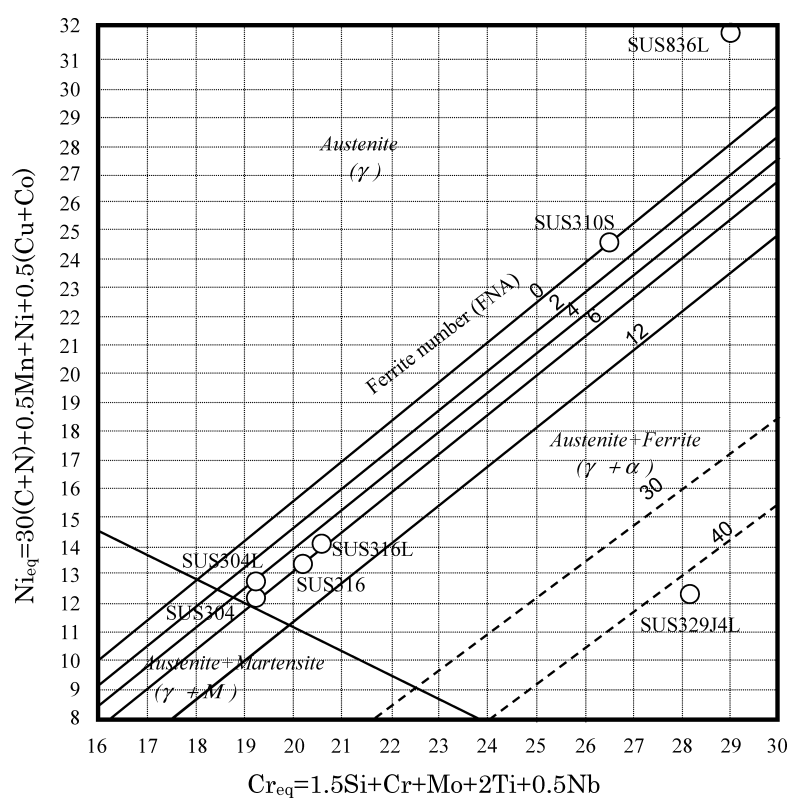

Fig. 5. DeLong diagram showing a various stainless steels.

enough in the environment containing $\mathrm{Cl}^{-}$ions more than $10^{4}$ ppm with an affordable cost. ${ }^{2)}$

The PRE (pitting resistance equivalent) value defined as the following equation is a measure of corrosion resistance.

$$
\mathrm{PRE}=(\operatorname{mass} \% \mathrm{Cr})+3.3(\operatorname{mass} \% \mathrm{Mo})+20(\operatorname{mass} \% \mathrm{~N}) . .
$$

For this alloy PRE higher than 45 is preferable under the environments for which this alloy is applied. Solidification structure after welded can be predicted referring to the DeLong diagram (JIS Z 3119-2006) shown in Fig. 5. SUS836L would have single austenite phase with no ferrite while the other grades with some amount of ferrite. It is generally recognized that single austenite phase may bring significant segregation leading to hot-cracking occasionally.

Figure 6(a) shows a cross-section of the welded strips by TIG with non-filler after pitting test. Significant extent of corrosion is obvious on the bead. In Fig. 6(b) the darker area shows the corroded area whose initiations were the dendrite cores. Figure 7(a) shows the distributions of PRE calculated with $\mathrm{Cr}$, Mo and $\mathrm{N}$ contents at the cross section of Fig. 7(b) prior to the pitting test. The PRE values were

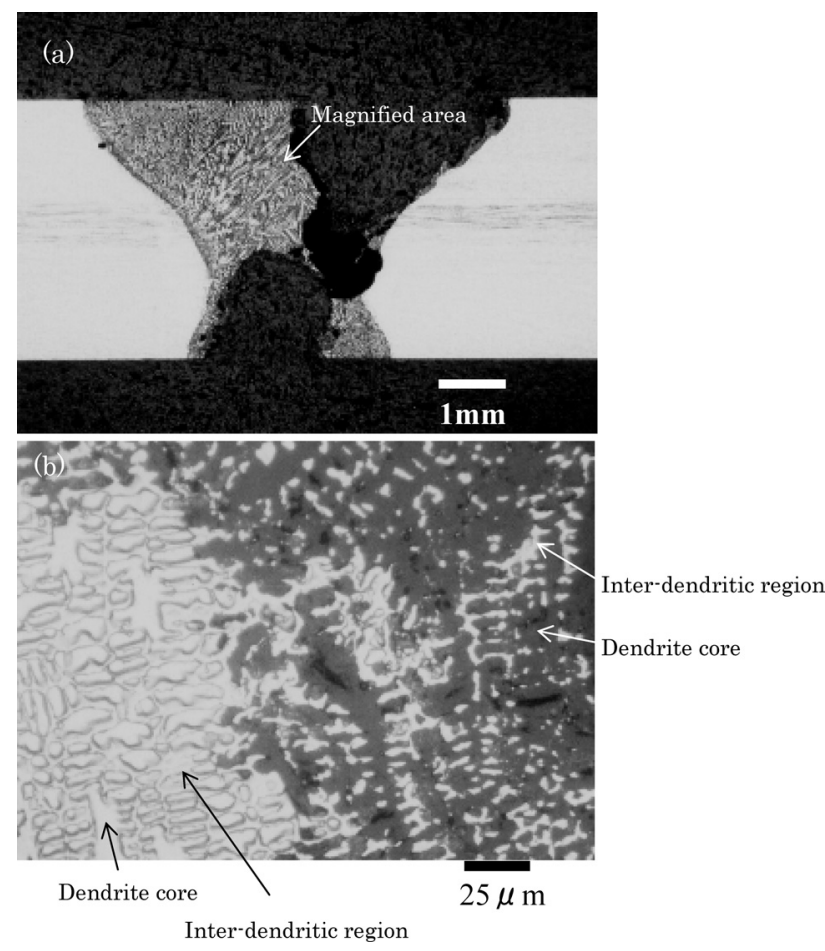

Fig. 6. (a) A cross-section of weld of SUS836L strips with nonfiller after the pitting test at $70^{\circ} \mathrm{C}$ and (b) a magnified structure of the specified point in (a).

calculated with constant $\mathrm{N}$ values of 0.205 mass $\%$ because the measurement of $\mathrm{N}$ distribution was impossible. The PRE values lower than 45 are seen along with the larger variations in the bead. As explained in Fig. 7(c), the higher PRE positions correspond to inter-dendritic regions. Since $\mathrm{Cr}$ and Mo are ejected from the primary austenite, the PRE values become lower on the dendrite cores. This implies that segregation causes worse corrosion resistance.

To improve the corrosion resistance in the bead, a higher grade of filler material than the strip is employed. When using ERNiCrMo-4 (57mass\% $\% \mathrm{Ni}-16$ mass $\% \mathrm{Cr}-16 \mathrm{mass} \%$ Mo-4mass $\% \mathrm{~W}-\mathrm{Fe}$ ) whose PRE is 69 , welding was successful enough without any failures as shown in Fig. 8. In Fig. 9 the PRE values are beyond targeted 45. Further no pitting occurred even in the bead. Recently, another filler material (Fe-35mass\%Ni-23mass\% $\%$ r-7.5mass $\% \mathrm{Mo}-0.22$ mass $\% \mathrm{~N}$ ) featuring lower Ni content than ERNiCrMo-4 has been developed to reduce the cost. Successful results were obtained with a series of experiments.

\subsection{Hot-workability}

Figure 10 shows the liquidus and solidus temperatures along with the other studies. ${ }^{9,10)}$ The liquidus temperature linearly decreases with increasing boron content and solidus temperature is almost constant at $1250^{\circ} \mathrm{C}$ over 0.6 mass $\%$ B. This is an evidence of eutectic behavior consistently with the solidification structure shown in Fig. 11. The primary austenite has morphology of dendrites. The dendrites and the borides are obviously finer in the case of the as-cast CC slab observing with SEM thanks to higher cooling rate of the $\mathrm{CC}$ slabs than the ingots. EPMA measurement has shown that the borides are $(\mathrm{Fe}, \mathrm{Cr})_{2} \mathrm{~B}$, a solid solution of $\mathrm{Fe}_{2} \mathrm{~B}$ and $\mathrm{Cr}_{2} \mathrm{~B}$ compounds. This result agrees with the other studies. 9,10$)$ 

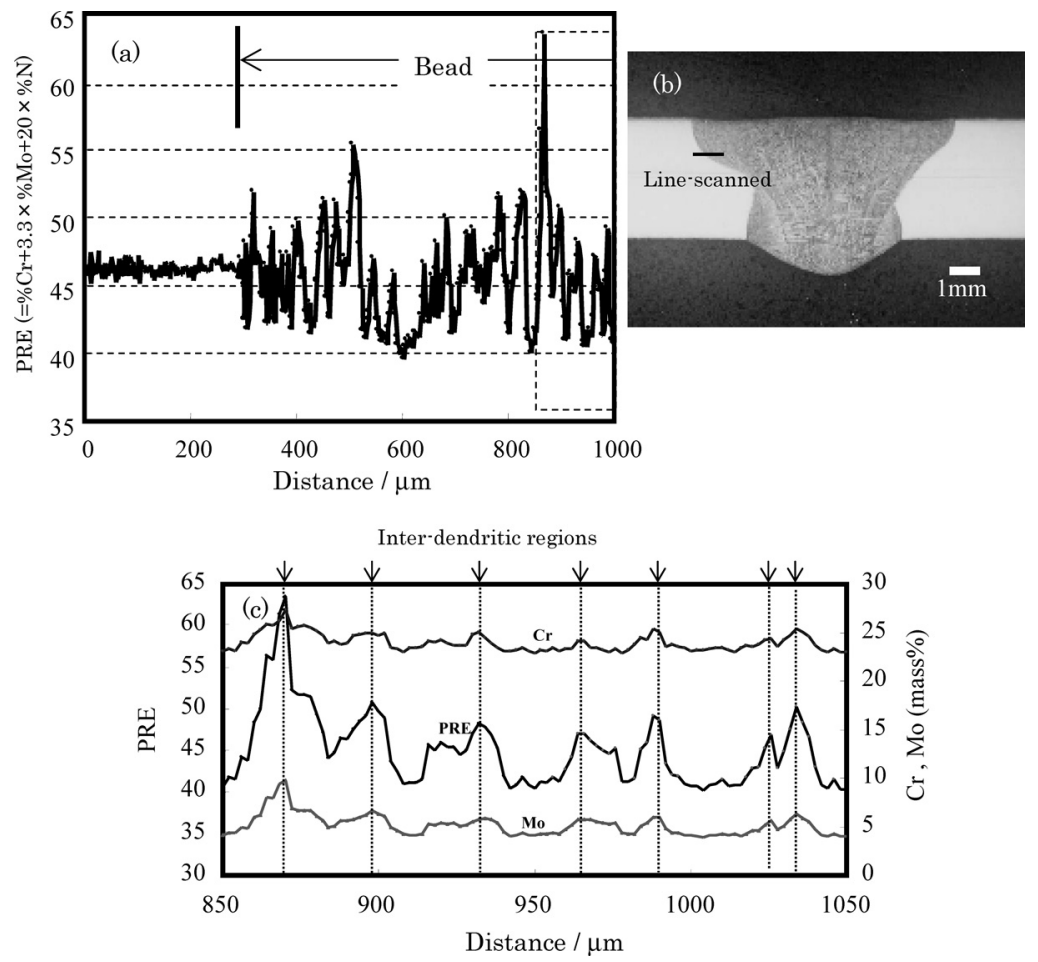

Fig. 7. (a) Distribution of PRE at the cross section (b) of the welded metal and (c) Cr, Mo and PRE distributions of the marked square of (a).

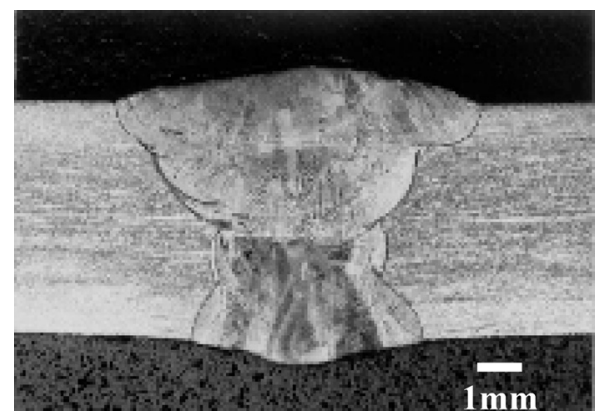

Fig. 8. A cross-section of weld of SUS836L strips using YNiCrMo-4 (NW0276) as a filler material.

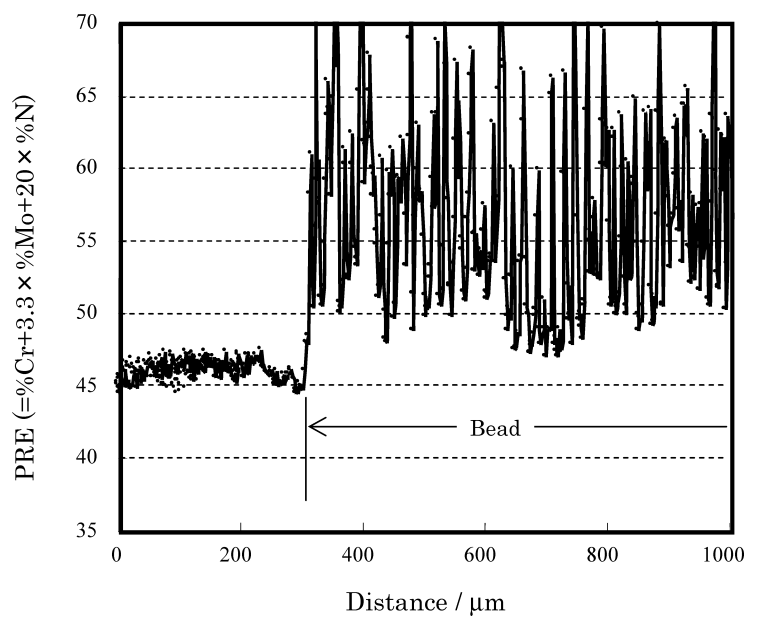

Fig. 9. Distribution of PRE obtained by the line scans of $\mathrm{Cr}$, Mo and $\mathrm{N}$ by EPMA in welded metal when using ERNiCrMo-4 as a filler material.

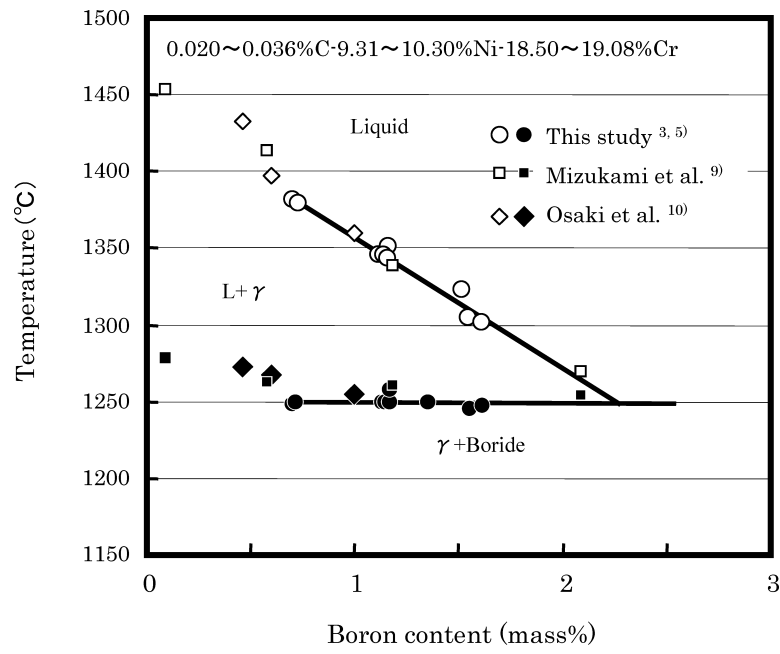

Fig. 10. Liquidus and solidus temperatures of the stainless steel containing boron. The open and solid marks show liquidus and solidus temperatures, respectively.

Ductility behavior is shown in Fig. 12 evaluating reduction of area. It is obvious that better is the case of the ascast CC slabs over the temperatures tested. When the crosssections of the fractured specimens were observed, voids which were considered as the initiation of cracks leading to fracture could be found at the interfaces between boride and austenite in Figs. 13(a) and 13(b). Besides, cracks are also seen inside the borides for both cases. The mechanism of fracturing behavior is considered as follows; strain and stress concentrates on the hard borides when deformed resulting in detachment of a boride from austenite as well as internal fracture in the borides. This initiation will eventually lead to the macroscopic cracking by connecting each other. 


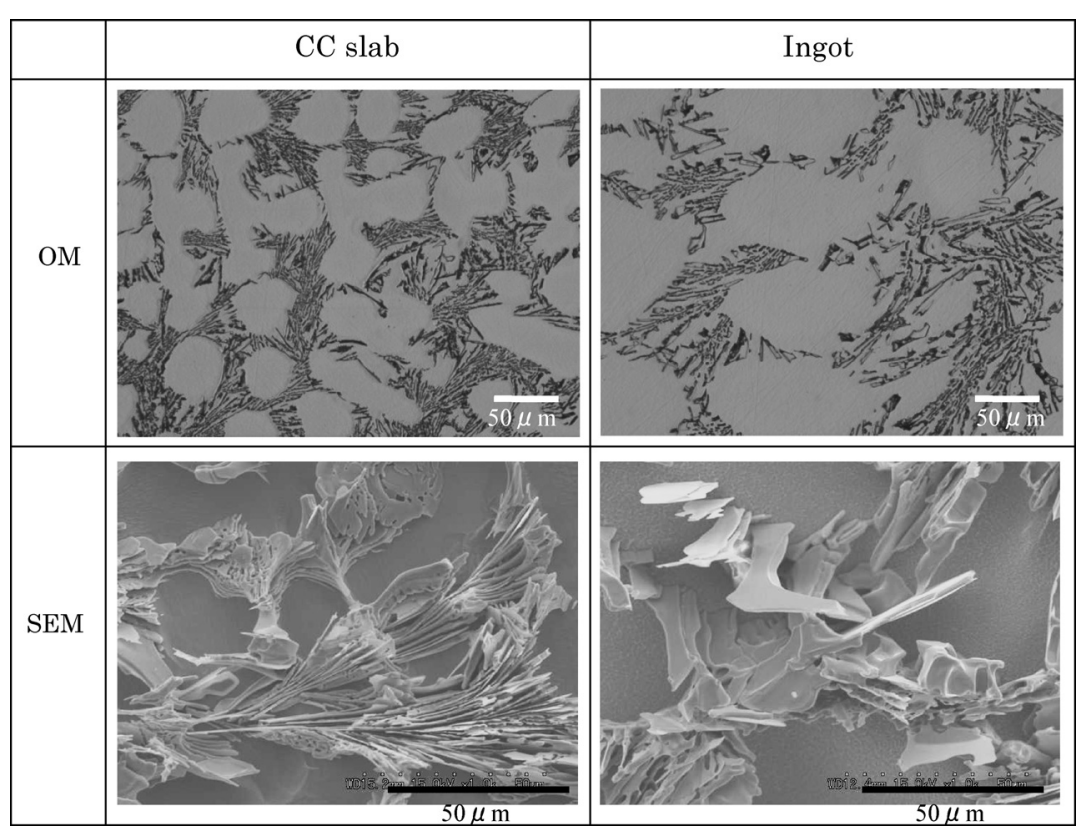

Fig. 11. Solidification structures of CC slab and ingot samples observed by an optical microscope (OM) and SEM.

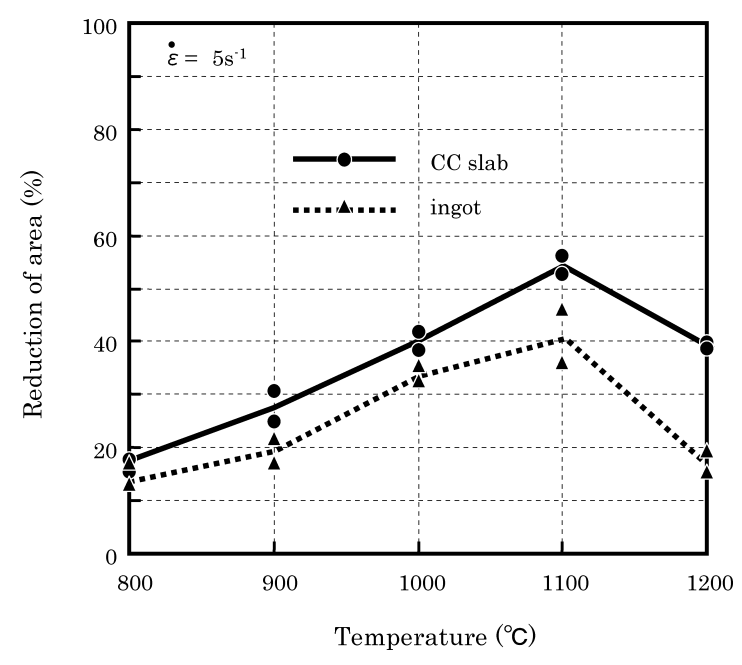

Fig. 12. Reduction of area after the high-temperature tensile tests.

It should be noticed that more voids exist in the ingot specimen and that most of voids form within the eutectoids. The eutectoids in the CC slab are much finer than in the ingots. This is why strain and stress may disperse more effectively for the CC slab. As a result, the production through the $\mathrm{CC}$ process is more advantageous to prevent cracking occurring at hot-rolling.

\subsection{Investment Casting}

A typical indication by magnetic particle testing appeared at the stem part is schematically shown in Fig.14. The indications always appeared at the stems closest to one of the sprues. To understand how the indication appeared, a specimen was taken cutting along the $\mathrm{A}-\mathrm{A}^{\prime}$ line in Fig. 14. The cross-section with no etch proves that the indication is attributed to a crack as shown in Fig. 15(a). EDS analysis showed that scale consisted of iron oxide existed inside the crack. This implies that this part has been cracked at relatively high temperatures probably during or immediately after solidification.
Figures 15(b)-15(d) show the illustration, magnified and macroscopic views of the solidification structure, respectively. It has to be noted that no apparent dendrite grows from the position with the crack and that this tendency is not enhanced at the other stem. The crack is surrounded by the dendrites grown from the other directions as comprehensively explained in Fig. 15(b). This may imply that this stem part close to the sprue became a "hot spot" while the molten steel filled the mold. When the molten steel flow is taken into consideration, the molten steel continuously hit this stem corner during filling through the sprue. The sprues were first designed as large as possible considering filling time.

A mold was then redesigned with a narrower sprue not to hit the stem. Figures 16(a) and 16(b) show the illustration and the solidification structure of an improved cast, respectively. As a result, no defect was detected by the inspection. Besides, some dendrites grow from this stem part. Eventually, the rejection problem by this cracking was completely solved. In addition to the crack, relatively strong segregation was seen especially at the center line due to columnar dendrites in Fig. 15. Ti of about 0.03 mass\% was simultaneously added to have equi-axed dendrites. Apparently, equiaxed dendrites are dominant in Fig. 16(b). This should be attributed to TiN formation which acts as a nucleation site of primary delta ferrite. ${ }^{11)}$

\section{Prospects}

As demonstrated above, for high alloys, solidification process still depends on the way of try and error and experience base. For example, cooling rate during solidification is almost fixed in order depending on the apparatus. When one would like to control solidification structure, the mold material or the equipment for cooling has to be replaced. This may be accomplished case by case. Sometimes this kind of replacement may be costly.

It is considered that relatively wider range of control is possible in foundry. A change in mold material may not be 
(a) CC slab (R.A.=42\%)

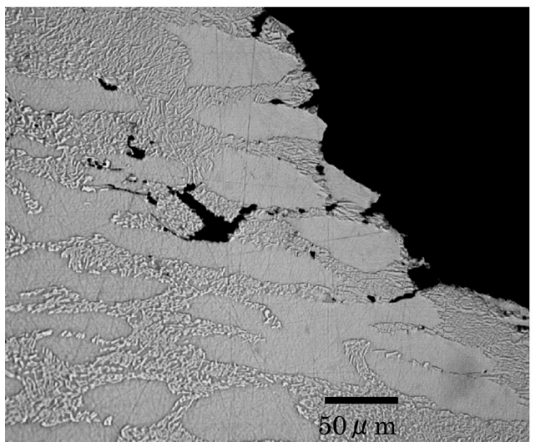

(b) Ingot (R.A.=33\%)

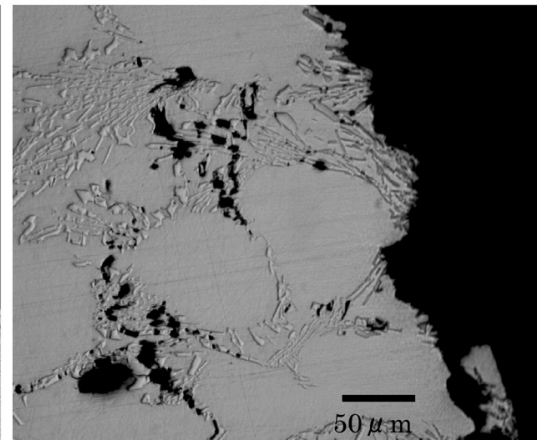

Fig. 13. Cross-sections of the fractured samples taken from (a) CC slab and (b) ingot.

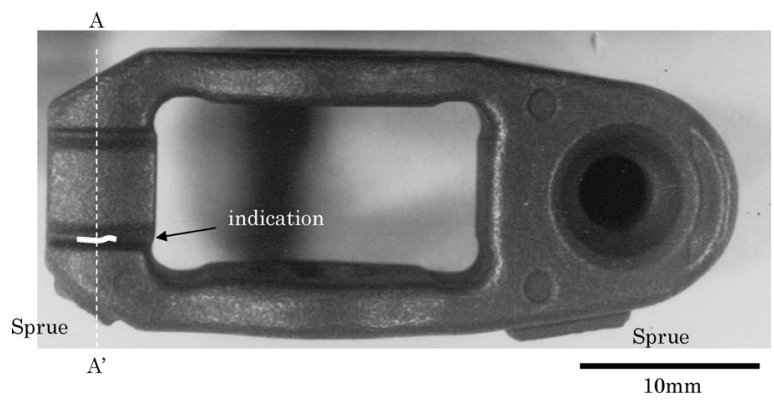

Fig. 14. A typical indication inspected by magnetic particle testing.

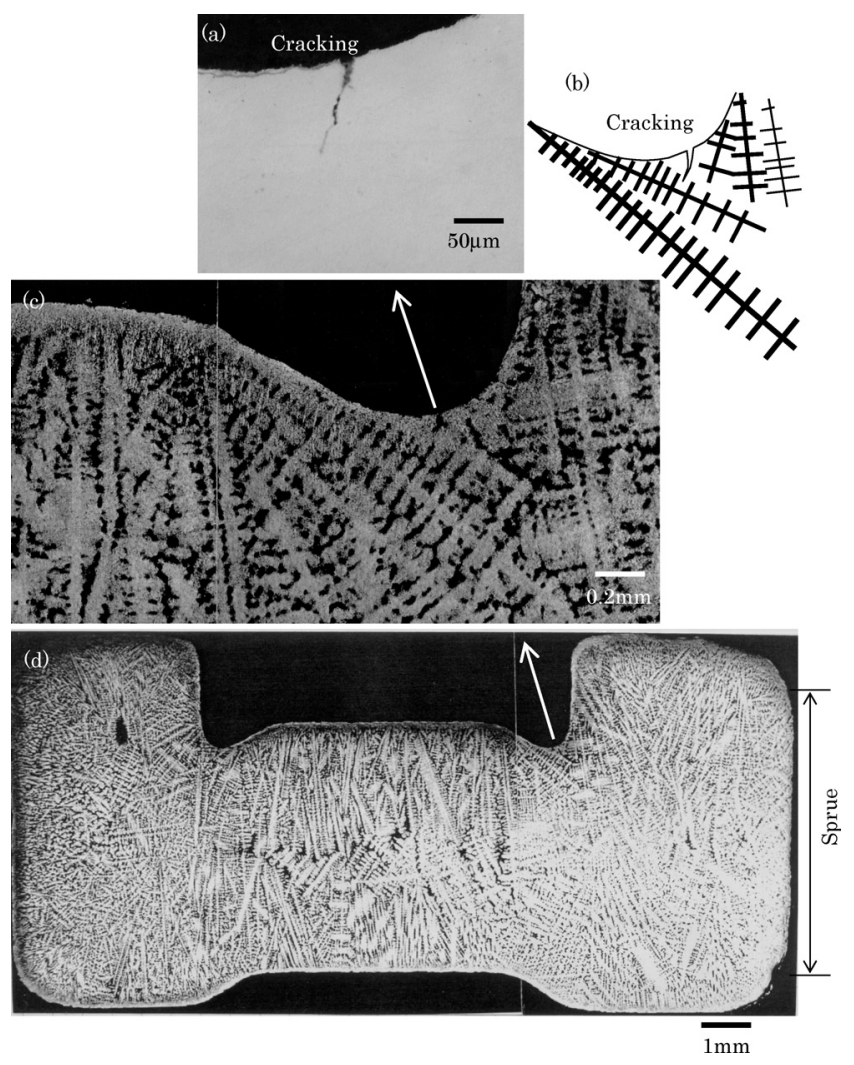

Fig. 15. Cracking appeared at the stem part showing (a) the cracking, (b) an illustration, (c) magnified and (d) whole views of the solidification structure at the cross-section cut along $\mathrm{A}-\mathrm{A}^{\prime}$ of Fig. 14.

difficult because of less costly than in continuous casting process. Besides, a variety of designs are quite possible in foundry to have sound products. Precise prediction prior to the production is strongly expected to avoid any defects.
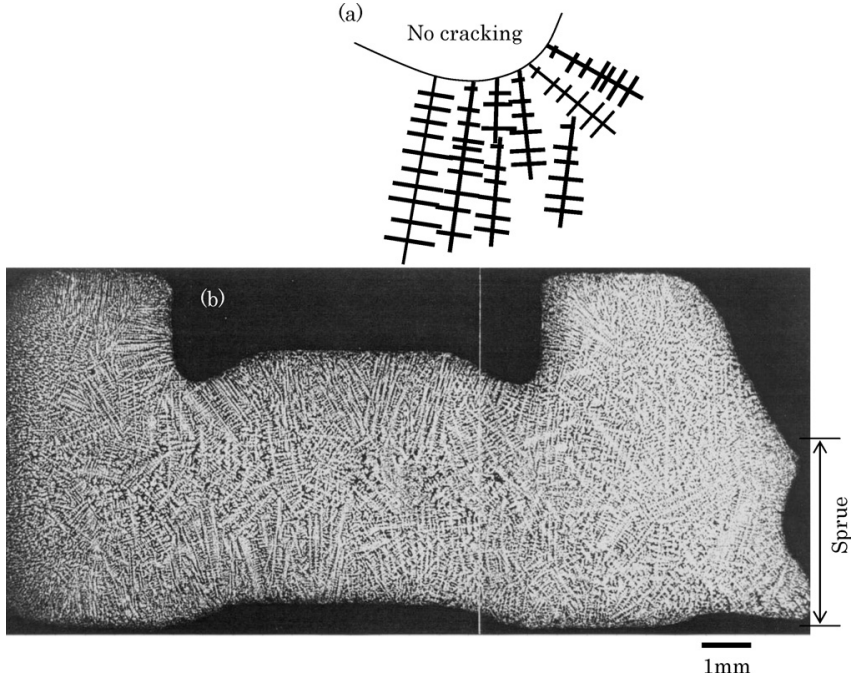

Fig. 16. (a) An illustration showing no cracking and (b) a whole cross-section of an improved casting.

When focusing on the $\mathrm{CC}$ process, this sort of change may mean almost renewal. For example, an electric magnetic stirrer (EMS) must be equipped when equi-axed grains are desired. However, some primitive parameters are left for the control to obtain desired structure. They include superheat of the molten steel, temperature and specific amount of cooling water. More equi-axed grains are possible with lower superheat. However, maintaining the molten steel temperature is getting more difficult. Clogging of an immersion nozzle may also take place due to lower temperatures. Comparing with foundry the controllable range is much narrower. But much attention is expected on how one controls these parameters to obtain a desired structure depending on the steel grades.

For welding, one can control the cooling rate changing the welding condition. However, the range of change will be limited. It is well-known that $\mathrm{Ti}$ addition significantly improves the structures of the weld in the case of carbon steel. ${ }^{12)}$ For specialty steels, research regarding the effect of minor elements on the weld structure is still not enough. More investigation is indeed expected for this view.

\section{Summary}

Three different phenomena related to solidification processing, which are welding, hot-workability and investment casting have been documented. The following comments 
summarize this report.

(1) With non-filler welding of SUS836L strips by TIG, segregation of welded material deteriorated corrosion resistance. Employing filler material with higher PRE improved this deterioration.

(2) Hot-workability of a stainless steel containing 1.1 mass \% boron was more excellent with CC slabs than ingots. This reason is attributed to the fact that the eutectoids are much finer with the CC slab.

(3) Cracks at the stem-like corners of investment casts were almost always took place. The cracking was improved by changing the size of sprues.

(4) For high alloys, solidification process still depends on the way of try and error and experience base. Therefore more investigations are expected to predict how molten steels solidify avoiding any defects and deterioration of every property.

\section{REFERENCES}

1) K. Wang: J. Jpn. Weld. Soc., 76 (2007), 80.

2) Y. Kobayashi: No. 228 Report of the Corrosion Resistance Committee, The Society of Materials Science, Japan, 41, (2002), 24.

3) T. Ishii, H. Todoroki, M. Oikawa, K. Mizuno, A. Hongo and A. Tanaka: CAMP-ISIJ, 14 (2001), 162.

4) M. Oikawa, T. Ishii, H. Todoroki and M. Moro-oka: CAMP-ISIJ, 15 (2002), 1298.

5) M. Tsubota and M. Oikawa: Bull. Iron Steel Inst. Jpn., 10 (2005), 929.

6) Y. Kobayashi: Stainless Steel World, KCI Publishing BV, Netherland, (2004), 425.

7) M. Oikawa and Y. Fujiwara: Nippon Yakin Technical Reports, 6 (1997), 10.

8) M. Oikawa, Y. Fujiwara and T. Tohge: CAMP-ISIJ, 9 (1996), 1238.

9) H. Mizukami, S. Hiraki, M. Kawamoto and T. Watanabe: Tetsu-toHagané, 85 (1999), 295.

10) K. Osaki and Y. Kawai: Nisshin Steel Tech. Rep., 57 (1987), 64.

11) B. L. Bramfitt: Metall. Trans., 1 (1970), 1987.

12) T. Koseki: Tetsu-to-Hagané, 90 (2004), 61. 